\title{
MONITORAMENTO DA EDUCAÇÃO INFANTIL PÚBLICA: POSSIBILIDADES E CONTEÚDOS
}

ELIANA BHERING

BEATRIZ DE OLIVEIRA ABUCHAIM

\section{RESUMO}

Este artigo apresenta a primeira etapa do processo de construção de um sistema de monitoramento para uma rede pública de educação infantil (EI) do município do Rio de Janeiro. Partindo de concepções teóricas a respeito de avaliação e monitoramento, foram avaliadas 149 unidades escolares. A coleta de dados seguiu o modelo das escalas de avaliação de ambientes e a análise foi realizada de acordo com a Teoria Clássica das Medidas. $O$ objetivo centrou-se em extrair aspectos relevantes para $O$ monitoramento das políticas da EI do município em questão. A análise dos dados incluiu também a compilação de informações de diferentes fontes sobre o funcionamento da rede municipal. Foram identificadas sete dimensões para a composição do monitoramento das políticas e práticas educativas, além de aspectos que podem contribuir para a methoria do atendimento nas unidades de ensino de EI. 


\section{RESUMEN}

Este artículo presenta la primera etapa del proceso de construcción de un sistema de monitoreo para una red pública de educación infantil del municipio de Rio de Janeiro. Partiendo de concepciones teóricas sobre evaluación y monitoreo, se evaluaron 149 unidades escolares. La recogida de datos siguió el modelo de las escalas de evaluación de ambientes y el análisis se llevó a cabo de acuerdo con la Teoría Clásica de las Medidas. El objetivo estuvo centrado en extraer aspectos relevantes para el monitoreo de las políticas de la educación infantil del municipio elegido. El análisis de datos también incluyó la recopilación de informaciones de distintas fuentes sobre el funcionamiento de la red municipal. Se identificaron siete dimensiones para la composición del monitoreo de las políticas y prácticas educativas, además de aspectos que pueden contribuir para mejorar la atención en las unidades de enseñanza de educación infantil.

PALABRAS CLAVE EDUCACIÓN INFANTIL • POLÍTICAS PÚBLICAS • MONITOREO • EVALUACIÓN.

\section{ABSTRACT}

This article presents the first stage in the process of constructing $a$ monitoring system for a public network of early childhood education in the city of Rio de Janeiro. Beginning with theoretical concepts regarding evaluation and monitoring, 149 individual school units were evaluated. Data collection followed the environmental rating scales model, and analysis was performed according to the Classical Theory of Measurement. The goal was focused on extracting aspects relevant to the monitoring of early childhood education policies of the city in question. Analysis of the data also included the compilation of information from different sources about the functioning of the municipal network. Seven dimensions were identified for the composition of monitoring educational policies and practices, in addition to aspects that could contribute to improving the services of early childhood education schools.

KEYWORDS EARLY CHILDHOOD EDUCATION • PUBLIC POLICIES • MONITORING • EVALUATION. 


\section{INTRODUÇÃO}

O Ministério da Educação (MEC) propôs, em 2009, um estudo sobre a qualidade do atendimento em unidades de educação infantil (EI) em seis capitais brasileiras. O intuito era verificar a situação de creches e pré-escolas depois da implementação de uma série de políticas que visavam a responder às diretrizes estabelecidas pela Constituição Federal de 1988. Esse estudo, o primeiro a avaliar a EI no Brasil, foi conduzido pela equipe da Fundação Carlos Chagas (CAMPOS et al., 2010), em parceria com o MEC e o Banco Interamericano de Desenvolvimento (BID). Os resultados apontaram o comprometimento da qualidade da EI, além de variações desse quesito de capital para capital, o que implicava um impacto no ensino fundamental (conforme avaliado pela Provinha Brasil, dado considerado no estudo). Em virtude desse diagnóstico, retomaram-se as discussões sobre os conceitos e o desenvolvimento da qualidade da EI, o que, por sua vez, provocou mais reflexões sobre o assunto. $O$ tema passou a ser discutido tanto no âmbito qualitativo quanto no quantitativo, desencadeando um posicionamento do MEC em relação 
à concepção de avaliação de sistema de EI (BRASIL, 2012) com base nas concepções de infância, criança e educação infantil, já apresentadas em publicações anteriores, ${ }^{1}$ e outros estudos que realizaram a análise de alguns instrumentos de avaliação da EI.

O estudo de Campos et al. (2010) foi sucedido pelo trabalho de Bhering et al. (2013), que também se propôs a refletir sobre a concepção e os resultados da pesquisa sugerida pelo MEC. Os objetivos, no entanto, incluíam ainda a avaliação da qualidade dos ambientes de uma amostra representativa das unidades públicas de um dos municípios envolvidos no estudo anterior, utilizando os mesmos instrumentos (ITERS-R e ECERS- ${ }^{2}$ ). Além disso, propunha a identificação de aspectos que pudessem compor o sistema de monitoramento (SM) das políticas municipais da EI com base em uma análise específica dos resultados da avaliação das unidades.

O projeto aqui apresentado é parte desse estudo, que contou com a participação ativa dos profissionais da Secretaria Municipal de Educação (SME) em suas diversas etapas, tais como discussão sobre a estrutura, elaboração e desenvolvimento do projeto, coleta e análise dos dados da avaliação. O trabalho compreendeu também o desenvolvimento de ações de formação sobre qualidade da EI e estratégias de avaliação e monitoramento da rede municipal para membros das equipes tanto da Secretaria quanto das regionais e unidades. O objetivo principal dessas ações foi esclarecer dúvidas a respeito dos temas "qualidade e avaliação da EI" e discutir sobre a realidade da rede municipal colocando sempre em perspectiva a qualidade do trabalho com as crianças.

Com base nas informações obtidas nas ações de formação e nos resultados das avaliações das unidades, objetivou-se elaborar recomendações para a melhoria da qualidade das práticas e dos projetos pedagógicos e das políticas municipais para a EI e propor o modelo inicial de um SM das políticas da EI, incluindo o envolvimento dos níveis central e regional e das unidades educacionais. O foco de discussão deste artigo será, desse modo, a reflexão realizada para subsidiar a condução do estudo e os resultados das análises com vistas à elaboração da proposta de conteúdo e concepção do SM.
1 Para mais informações, conferir publicações do MEC na área de El disponíveis em seu portal na internet: <http://portal.mec.gov.br/ index.php?option=com_content $\& v i$ ew $=$ article $\& i d=12579 \% 3$ Aeducacaoinfantil\&Itemid=1152>

2 Escala original: Harms, Clifford e Cryer (2005, 2006) 


\section{REVISÃO BIBLIOGRÁFICA}

Os critérios de qualidade para o atendimento na EI têm motivado numerosas discussões de pesquisadores e profissionais da área há pelo menos duas décadas. Na mesma linha desses debates, várias publicações do MEC foram feitas a fim de estabelecer parâmetros comuns de funcionamento das instituições de EI tanto no que diz respeito a aspectos de infraestrutura quanto no que se refere aos processos educativos (CAMPOS; ROSEMBERG, 1995; BRASIL, 2006, 2009).

O processo de avaliação da qualidade desse nível de ensino apresenta-se como desafio à produção acadêmica nacional, disparando também discussões relacionadas à prática pedagógica. Essa preocupação está refletida nas iniciativas do Instituto Nacional de Estudos e Pesquisas Educacionais Anísio Teixeira (Inep) e do MEC em busca de um sistema de avaliação da qualidade da EI que considere suas especificidades e que seja orientado para a avaliação de ambientes e não das crianças. Em 2012, o MEC criou um grupo de trabalho para elaborar orientações para que, posteriormente, o Inep, juntamente com um grupo de especialistas, desenvolvesse uma proposta de avaliação da EI. O trabalho intitulado "Educação infantil: subsídios para construção de uma sistemática de avaliação" (BRASIL, 2012) foi elaborado e discutido por vários representantes de órgãos públicos, associações, universidades e movimentos sociais. Diferentemente de outras etapas de ensino, afirma-se que o parâmetro segundo o qual se deve estimar a qualidade de atendimento na EI é a avaliação dos sistemas e não a avaliação da aprendizagem das crianças. Esse posicionamento revela a preocupação em prover condições adequadas para todas as crianças de 0 a 5 anos de idade, reforçando que, em uma sociedade democrática, a qualidade da educação é um direito inalienável de todos os cidadãos, sem distinção (GENTILI, 2001). Infere-se, dessa maneira, que, por considerar um conjunto de dimensões, um trabalho de boa qualidade na EI garantiria a experiência adequada para as crianças nessa etapa da educação básica.

Salienta-se também a importância de avaliar o acesso à EI, os insumos (como orçamento, espaço físico, recursos humanos, recursos materiais) e os processos que dão "destaque 
a aspectos relativos a gestão, currículo, relações/interações, prática pedagógica que se espera estejam presentes na educação infantil” (BRASIL, 2012, p. 24). Assim, a avaliação da EI se propõe a ir além de um simples diagnóstico de uma rede ou de uma unidade. Ela se apresenta como subsídio para um caminho possível de aprimoramento do trabalho nas redes e instituições, uma vez que lança luz sobre diferentes aspectos do atendimento e procura nortear a implementação de uma política pública destinada a bebês e crianças pequenas:

Nesse sentido, considera-se que a avaliação deve envolver o grupo de profissionais das unidades, desafiando-os a fazer uma observação de suas práticas cotidiana, por meio de instrumentos que sistematizem essa observação. A partir dos dados coletados, a avaliação pode promover uma reflexão sobre o trabalho desenvolvido e estimular a busca pela melhoria da qualidade (BECCHI; BONDIOLI, 2003).

Desse modo, a avaliação da EI pode contribuir para a reflexão de gestores e educadores sobre o trabalho desenvolvido nas unidades. Conforme aponta Bondioli (apud BECCHI; BONDIOLI, 2003, p. 57-58):

É possível realizar um processo de avaliação, utilizando uma série de instrumentos como diretrizes para o olhar e para a identificação de aspectos relevantes das práticas educativas, com a intenção, não tanto de chegar a um juízo de maior ou menor qualidade das escolas examinadas, mas, sim, de favorecer um processo de conscientização das professoras de aquisição de maior consciência em relação às escolhas feitas, às inovações realizadas ou a serem realizadas, ao significado educativo do que se faz nas escolas para as crianças.

Partindo da premissa de que a avaliação da EI deve centrar-se no acesso, nos insumos e processos, espera-se formular uma proposta de monitoramento das redes públicas que sirva, essencialmente, como ferramenta de gestão para o aprimoramento dos sistemas de ensino. Ao considerar a avaliação e o monitoramento da qualidade da EI, é preciso examinar também instrumentos que ressaltam as diversas dimensões que compõem o serviço nesse nível de ensino, tais como as 
mencionadas, por exemplo, nos Indicadores da qualidade da educação infantil (BRASIL, 2009): planejamento institucional; multiplicidade de experiências e linguagens; interações; promoção de saúde; espaços, materiais e mobiliários; formação e condições de trabalho dos profissionais; cooperação e troca com as famílias e participação na rede de proteção social. As dimensões, mesmo com nomenclaturas diferentes, são encontradas em vários outros instrumentos, como nas escalas utilizadas neste estudo (ITERS-R e ECERS-R).

Ao tratar de avaliação e monitoramento, é importante, no entanto, diferenciar o conceito de cada um dos termos. Há diversos tipos de avaliação educacional que não são propriamente excludentes: avaliação das ações, dos programas e projetos; da aprendizagem; da instituição e de pessoal. Cada uma dessas formas de avaliação cumpre uma função: diagnóstica, formativa ou somativa. É importante verificar as possibilidades de cada forma, adequando-a aos objetivos a serem atingidos.

Bloom (2008) define monitoramento e avaliação como processos de coleta e análise de dados que fornecem aos gestores importantes informações sobre a implementação e os resultados de um programa. A avaliação é usada para demonstrar se o programa atingiu suas metas e obteve os resultados esperados. E pode estar focada no processo de implementação, nos resultados (se ele atingiu ou não os objetivos) ou em seu impacto (se ele representa um fator que contribuiu para a mudança de uma realidade). Ao passo que o monitoramento é considerado um acompanhamento rotineiro do progresso de um programa, em que dados são coletados regularmente, de modo a verificar se as atividades planejadas estão sendo implementadas de forma satisfatória. As informações provindas do monitoramento auxiliam os gestores a entenderem melhor como o programa está se desenvolvendo no dia a dia. De acordo com Mokate (2002, p. 91), o Fundo das Nações Unidas para a Infância (Unicef, 1991) define "monitoramento como um acompanhamento sistemático e periódico da execução de uma atividade, que busca determinar o grau em que seu desenlace coincida com o programado, com o fim de detectar oportunamente deficiências, obstáculos e/ou necessidades de ajuste da execução". 
Claramente, os objetivos, ao se conduzir uma avaliação e ao se propor um monitoramento, são diferentes, em especial quando se consideram as diversas possibilidades de ambas as ferramentas: a avaliação pode ser externa, interna ou constituir-se como autoavaliação; o monitoramento, por sua vez, prevê a elaboração cuidadosa de indicadores provenientes de complexos sistemas de informações e avaliações. Além disso, processos de avaliação e de monitoramento, quando se trata de políticas públicas, devem ser conduzidos de maneira distinta e produzem conjuntos de informações que servirão a diferentes propósitos.

De acordo com Januzzi (2009), ao considerar o ciclo de políticas, o monitoramento e a avaliação são processos analíticos e podem estar articulados e se complementarem de maneira a gerar informações que auxiliem gestores tanto na formulação das políticas quanto na prática. $\mathrm{O}$ autor diferencia também os indicadores de monitoramento dos indicadores da avaliação. Ao passo que os primeiros sintetizam as informações sobre o ritmo e a forma da implementação de um programa/política, os indicadores da avaliação apresentam seus resultados e efeitos.

\section{MÉTODO}

\section{CARACTERIZAÇÃO DA REDE MUNICIPAL DE EDUCAÇÃO INFANTIL DO RIO DE JANEIRO}

A SME do Rio de Janeiro oferece atendimento em: creches, que atendem crianças de 6 meses a 3 anos e 11 meses de idade; pré-escolas, responsáveis pelos alunos de 4 a 5 anos e 11 meses de idade; espaços de desenvolvimento infantil (EDIs), cuja proposta é atender crianças de 6 meses a 5 anos e 11 meses de idade em período integral; as escolas municipais, cujo alunado tem de 4 anos a 5 anos e 11 meses de idade, sendo que algumas também atendem crianças a partir de 3 anos; e centros integrados de educação pública (Cieps), destinados a crianças em idade de creche e pré-escola. A grande maioria das turmas de pré-escola está situada em escolas municipais de ensino fundamental de período parcial. O número de unidades que ofereciam matrículas na creche e/ou pré-escola em 2012 era de 1005. 
A rede pública de EI do município tem apresentado expressiva expansão no número de matrículas nos últimos cinco anos. Por exemplo, de 2010 a 2012 houve um aumento de aproximadamente dez mil vagas para a creche. No ano de 2012, quando a pesquisa foi realizada, 43.225 crianças estavam matriculadas em creches e 72.827 crianças, na pré-escola. Na época, havia 254 creches municipais, 44 EDIs, das quais 37 eram escolas que haviam sido transformadas em EDIs com maternal (totalizando 298 unidades municipais), além do atendimento em pré-escolas (e algumas classes de maternal) feito em 698 escolas municipais de ensino fundamental, de acordo com dados levantados junto à Secretaria Municipal de Educação no ano de 2013.

\section{PROCEDIMENTOS PARA O ESTUDO DE AVALIAÇÃO}

O estudo de avaliação da qualidade dos ambientes de EI foi realizado em uma amostra de unidades da rede municipal, com cerca de $17 \%$ das unidades que possuem turmas de creche e/ou pré-escola, resultando em um total de 149 instituições visitadas. Na composição da amostra, foram consideradas as seguintes variáveis: Coordenadoria Regional de Educação (foram incluídas unidades pertencentes a todas); tipo de atendimento (apenas creche; creche e pré-escola; pré-escola, ensino fundamental e outros); número de alunos (menos de 150; entre 150 e 600 e mais de 600) e período (menos de 6 horas/dia e 6 horas/dia ou mais). No total, foram avaliadas 116 turmas que apresentavam matrículas de crianças de 2 anos e meio a 5 anos e 11 meses de idade, utilizando a escala ECERS-R, e 45 turmas que apresentavam matrículas de crianças de 6 meses a 2 anos e meio de idade, empregando a escala ITERS-R.

A ITERS-R apresenta um roteiro de observação que reúne sete subescalas (espaço e mobiliário, rotinas de cuidado pessoal, falar e compreender, atividades, interação, estrutura do programa e pais e equipe), com 39 itens compostos por 455 indicadores. A ECERS-R oferece um roteiro que também reúne sete subescalas (espaço e mobiliário, rotinas de cuidado pessoal, linguagem e raciocínio, atividades, interação, estrutura do programa e pais e equipe), com 43 itens e 470 indicadores. Como forma de exemplificar a estrutura da 
escala, apresenta-se, no Anexo 1, uma página na escala ITERS-R: a subescala é "I. Espaço e mobiliário", do item 3, intitulado "Recursos para relaxamento e conforto", constituído por nove indicadores, que devem ser marcados pelo avaliador com "sim" ou "não".

Os indicadores estão qualitativamente ordenados em intervalos que variam de $1 \mathrm{a} 7$ pontos, dos quais as pontuações 1 e 2 correspondem a situações ou aspectos considerados inadequados, indicando um nível precário de qualidade; 3 e 4 aplicam-se a um conjunto de condições definidas como mínimas; 5 e 6 sinalizam a presença de condições classificadas como boas; e 7 corresponde ao que é considerado excelente. As unidades municipais do Rio de Janeiro foram avaliadas e pontuadas conforme instruções dadas pelas escalas, mas, para fins de análise adicional, que visava à identificação de aspectos relevantes para tal rede, feitas com o uso da Teoria Clássica de Medidas (TCM), foi utilizada a marcação individual de cada indicador de todos os itens que compõem as escalas (vide Anexo 1). A análise foi feita separadamente, de acordo com os resultados para as turmas de crianças de 6 meses a 2 anos e meio de idade; e para as turmas de crianças de 2 anos e 7 meses a 5 anos de idade em diante.

\section{PROCEDIMENTOS PARA A ANÁLISE ESTATÍSTICA COM O USO DA TEORIA CLÁSSICA DAS MEDIDAS}

Considerando os resultados obtidos em cada um dos indicadores (na escala ITERS-R, há 455 indicadores e na ECERS-R, 470), obteve-se informação importante para a elaboração de sugestões de conteúdo para o SM. Assim, foram definidas neste estudo algumas estratégias estatísticas para a análise desses dados. Com a utilização do software ITEMAN, foram obtidas estatísticas para cada um dos indicadores da TCM.

A adoção dessa abordagem teve o intuito de selecionar os indicadores em que os resultados observados se destacassem em relação aos demais, isto é, evidenciando em quais aspectos as instituições visitadas apresentaram as maiores diferenças, ou as maiores similaridades, ou, ainda, em quais deles os resultados afastavam-se do padrão esperado. $\mathrm{O}$ objetivo final foi reduzir o número de indicadores na 
tentativa de visualizar que aspectos eram mais relevantes para o monitoramento.

Para tanto, os indicadores foram tratados de maneira dicotômica, refletindo apenas a presença ou a ausência de cada aspecto abordado. Dessa maneira, indicadores que permitem marcar NA (não se aplica) foram excluídos da análise, exceto nos casos em que não foi observada nenhuma ocorrência de NA no indicador. Também existem alguns itens que permitem assinalar a alternativa NA para o item como um todo. Nesses casos, quando a porcentagem observada de NA foi considerada elevada (maior que 35\%), procedeu-se à exclusão do item inteiro. Assim, nem todos os indicadores puderam ser examinados nessa abordagem. Cabe ressaltar, contudo, que a quantidade de indicadores excluídos foi bastante reduzida.

As análises relativas a cada uma das subescalas foram realizadas separadamente. Dada a natureza dos instrumentos utilizados, os indicadores iniciais de cada um dos itens sempre retratam a inadequação dos aspectos investigados no item. Para efeitos da análise, essa relação foi invertida, de modo que a presença de qualquer um dos aspectos avaliados fosse considerada positiva. Assim, pontuações mais altas em quaisquer das subescalas revelam ambientes pertencentes a instituições de melhor qualidade.

Para cada um dos indicadores foram calculados: a proporção de instituições com presença de aspectos positivos, o índice de discriminação e a correlação ponto bisserial. A proporção de instituições que apresentam o aspecto investigado no indicador - conhecida na TCM como proporção de "acertos" - foi o primeiro tipo de informação considerado nesta análise, sinalizando quais eram os quesitos em que as instituições visitadas precisavam melhorar (quando a presença de determinado aspecto era muito reduzida ou praticamente nula) e, também, quais aspectos eram quase universais (quando esses valores eram altos ou próximos de um).

Para o cálculo do índice de discriminação, a amostra de instituições avaliadas foi dividida em três grupos (grupo superior, grupo do meio e grupo inferior), de acordo com o total de pontos alcançados na subescala. Aquelas que obtiveram 
as pontuações mais elevadas formaram o chamado "grupo superior" (GS), que abrangeu $27 \%$ das instituições. As que tiveram as pontuações mais baixas compuseram o "grupo inferior” (GI), que representou $27 \%$ das instituições. Calculou-se então o índice de discriminação, que é dado pela diferença entre o grupo superior e o inferior quanto à proporção de instituições situadas em cada um desses dois grupos que receberam pontos no quesito descrito no indicador. Quanto maior o índice de discriminação do indicador examinado, maior é a coerência entre esse indicador e os resultados obtidos na subescala pelas instituições.

A correlação ponto bisserial é uma medida de associação entre a presença do que está sendo investigado no indicador e a nota geral das instituições na subescala. Dessa forma, valores positivos e altos nessa medida significam que as instituições de EI em que se observou a presença do aspecto descrito no indicador apresentam os melhores desempenhos na subescala, o que é esperado intuitivamente. Por último, com o objetivo de identificar um conjunto mais reduzido de indicadores, dando origem a um instrumento mais adequado às atividades de monitoramento, foram adotados os seguintes procedimentos:

a) seleção dos indicadores de cada uma das sete subescalas de cada um dos dois instrumentos que apresentavam índices de discriminação iguais ou superiores a 0,50;

b) agrupamento desse conjunto de indicadores altamente discriminativos em subgrupos com maior afinidade em termos de seus temas centrais.

Por exemplo, conforme se demonstra na Tabela 1, os resultados relativos ao indicador 3.1 do item 18 - Música e movimento, da subescala atividades da ITERS-R (ambientes para crianças de 0 a 2 anos e meio de idade) - podem ser interpretados da seguinte maneira: $33 \%$ das instituições investigadas realizavam o que está escrito no indicador (\% de acertos). Dentre as instituições que obtiveram as pontuações mais elevadas na subescala atividades, pertencentes ao GS, $71 \%$ cumpriram o descrito no indicador, ao passo que nenhuma ( $0 \%$ ) das unidades pertencentes ao GI dessa subescala cumpriu o critério, ou seja, pontuou esse indicador. Isso leva 
a concluir que o índice de discriminação desse indicador é bastante alto (0.714), tendo um peso elevado na diferenciação entre as unidades com pontuações mais altas e as que obtiveram pontuações mais baixas nesse indicador. Ainda o valor do ponto bisserial (0.53) indica que as instituições que pontuam esse indicador têm uma tendência a um melhor desempenho nos critérios de qualidade da subescala atividades como um todo.

TABELA 1

\begin{tabular}{|c|c|c|c|c|c|c|c|}
\hline SUBESCALA & ITEM & DESCRIÇÃO DO INDICADOR & $\begin{array}{c}\text { ÍNDICE DE } \\
\text { DISCRIMINAÇÃO }\end{array}$ & $\%$ ACERTO & GI & GS & $\begin{array}{c}\text { PONTO } \\
\text { BISSERIAL }\end{array}$ \\
\hline Atividades & $\begin{array}{l}18 \text { - Música e } \\
\text { movimento }\end{array}$ & $\begin{array}{l}3.1 \text { - Diariamente, há alguns materiais, } \\
\text { brinquedos ou instrumentos musicais } \\
\text { acessíveis para atividade livre, } \\
\text { durante a maior parte do dia (ex.: } \\
\text { chocalhos, brinquedos de dar corda, } \\
\text { caixa de música, xilofone, tambor). }\end{array}$ & 0.714 & 0.333 & 0.000 & 0.714 & 0.530 \\
\hline
\end{tabular}

Esse tipo de informação é de extrema validade quando se pensa na elaboração de subsídios para um SM. Os aspectos a serem monitorados devem partir de experiências que já estejam colocadas em prática nas unidades, ou seja, que já façam parte da política para a EI do munícipio, estando descritas em documentos oficiais, como as Orientações curriculares para a educação infantil (RIO DE JANEIRO, 2010), e que, uma vez implementadas, tenham um valor importante na determinação da qualidade de atendimento das instituições. Como no exemplo dado, o indicador que descreve a presença em sala e a acessibilidade das crianças a materiais, brinquedos ou instrumentos musicais pode vir a ser um aspecto válido a ser monitorado em virtude do peso que apresentou ao diferenciar unidades com melhores ou piores avaliações de qualidade.

Por outro lado, aqueles aspectos pouco presentes nas salas avaliadas, mas importantes para a garantia de um atendimento de qualidade, como os indicados em documentos oficiais (municipais ou nacionais) sobre a EI, também devem ser considerados como metas para novas políticas e, por isso, incluídos em um SM. Por exemplo, se quase nenhuma sala 
avaliada apresenta materiais para Matemática e o trabalho com esse aspecto está fortemente indicado nas Orientações curriculares para a educação infantil (RIO DE JANEIRO, 2010), cabe pensar em um monitoramento que identifique tal aspecto, de maneira que a tomada de decisão sobre quais materiais adquirir para turmas de crianças da faixa etária em questão seja recomendada. Desse modo, o monitoramento deve ser compreendido como uma ferramenta que permita aos gestores de todos os níveis tomar decisões possíveis e adequadas a fim de suprir as necessidades da rede/unidade que administram. Implementado dessa forma, o monitoramento refuta as premissas de políticas de ranqueamento e premiação e leva em consideração a situação específica de cada unidade de ensino.

\section{RESULTADOS}

\section{ITERS-R}

$\mathrm{Na}$ análise clássica dos itens ${ }^{3}$ da escala ITERS-R, 109 indicadores foram selecionados como aqueles que mais diferenciaram as 45 salas observadas, conforme se verifica na Tabela 2 a seguir.

3 Os itens das escalas analisados são denominados "indicadores" de acordo com a própria nomenclatura usada originalmente pelos autores desses instrumentos (indicators). 


\begin{tabular}{|c|c|}
\hline DIMENSÕES - ITERS-R & $\begin{array}{l}\text { NÚMERO DE } \\
\text { INDICADORES } \\
\text { SELECIONADOS } \\
\text { PELA ANÁLISE }\end{array}$ \\
\hline $\begin{array}{l}\text { Práticas de cuidado: incluem indicadores que mostram se equipe está atenta aos } \\
\text { procedimentos de proteção à saúde e à segurança das crianças. }\end{array}$ & 21 \\
\hline $\begin{array}{l}\text { Organização do trabalho pedagógico: inclui uma larga variedade de aspectos } \\
\text { que descrevem as possibilidades criadas para o desenvolvimento do trabalho } \\
\text { pedagógico com crianças pequenas. }\end{array}$ & 16 \\
\hline $\begin{array}{l}\text { Atitudes da equipe: descreve como a equipe se relaciona com as crianças em } \\
\text { sala para promover um ambiente positivo e calmo e que, portanto, conduz a um } \\
\text { ambiente de aprendizagem adequado. }\end{array}$ & 16 \\
\hline $\begin{array}{l}\text { Acesso aos materiais: agrupa informações sobre a disponibilidade, acessibilidade e } \\
\text { adequação de materiais, brinquedos, equipamentos, livros, blocos e materiais para } \\
\text { música em sala. }\end{array}$ & 15 \\
\hline $\begin{array}{l}\text { Estratégias para desenvolvimento profissional: inclui aspectos relacionados à } \\
\text { formação continuada, à supervisão do trabalho pedagógico e às avaliações sobre o } \\
\text { desempenho dos profissionais realizadas pela unidade. }\end{array}$ & 10 \\
\hline $\begin{array}{l}\text { Conversas entre equipe e crianças: descreve como a equipe desenvolve diálogos } \\
\text { com as crianças, introduzindo coisas novas, respondendo às crianças e interpretando } \\
\text { suas ações, suas intenções e seus desejos. }\end{array}$ & 10 \\
\hline $\begin{array}{l}\text { Espaço e mobiliário: refere-se a alguns aspectos do espaço e de equipamentos } \\
\text { como sendo apropriados, suficientes, em boas condições e bem organizados. }\end{array}$ & 9 \\
\hline $\begin{array}{l}\text { Organização do tempo: descreve como o cotidiano é organizado de maneira } \\
\text { a favorecer os interesses e as necessidades das crianças, beneficiando sua } \\
\text { aprendizagem por meio de uma variedade de atividades. }\end{array}$ & 9 \\
\hline $\begin{array}{l}\text { Estratégias para envolvimento dos pais: diz respeito às estratégias utilizadas pela } \\
\text { equipe para envolver os pais na unidade, seja por meio de atividades ou trocas de } \\
\text { informação. }\end{array}$ & 3 \\
\hline TOTAL & 109 \\
\hline
\end{tabular}

Para a análise dos resultados dos indicadores selecionados, agruparam-se aqueles com maior afinidade em termos de temas centrais, criando novas dimensões. Esses agrupamentos foram reclassificados, tal como mostra a primeira coluna da tabela acima, gerando nove dimensões compostas por indicadores que variaram de 3 a 21 . As sugestões de itens/aspectos a serem considerados na construção de um SM foram, então, extraídas dos indicadores de cada dimensão após a identificação dos temas centrais de cada indicador, como será exemplificado a seguir, com a apresentação da dimensão "Acesso a materiais".

\section{ACESSO A MATERIAIS}

Os indicadores selecionados pela análise clássica estão listados na Tabela 3. 
TABELA 3

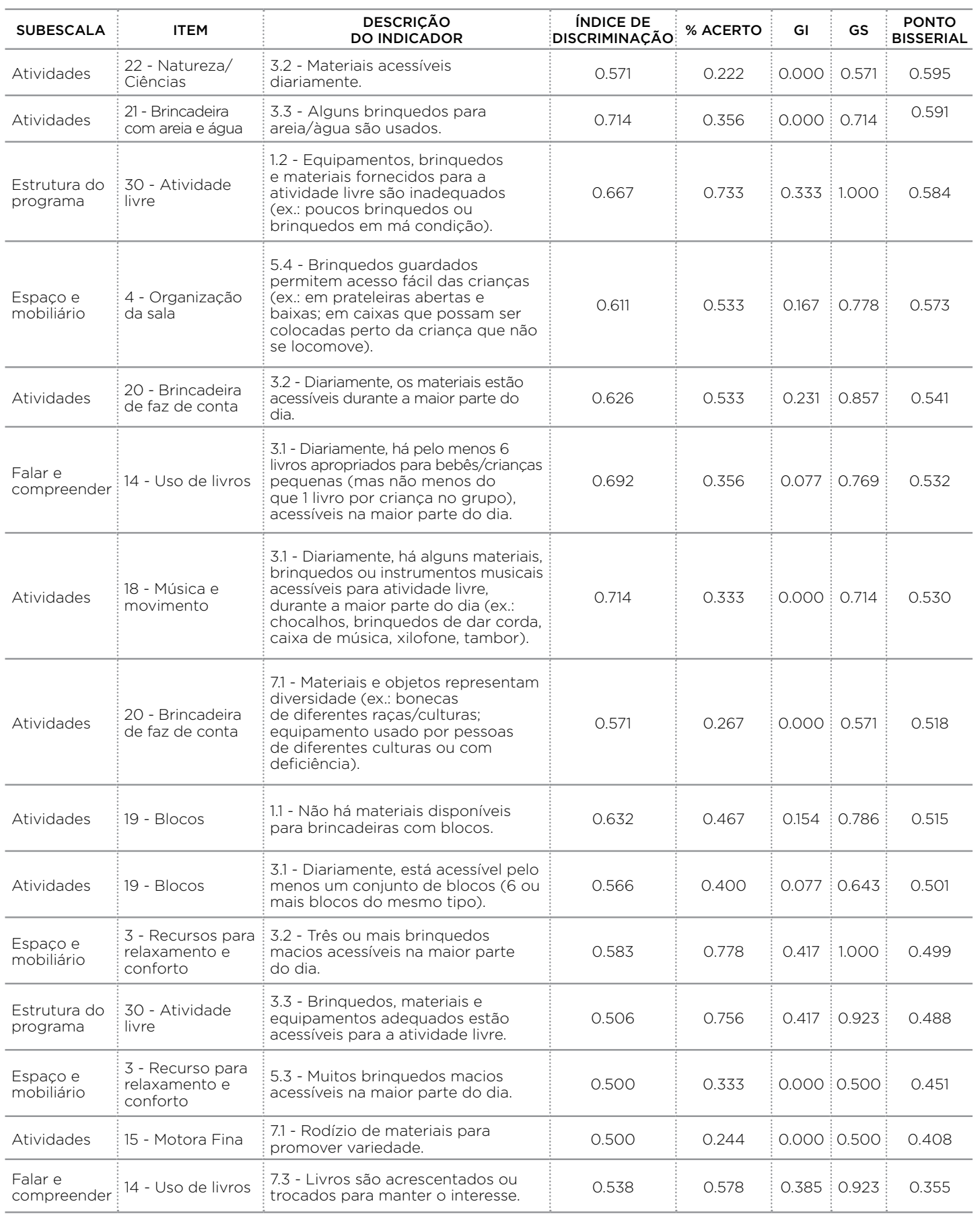


O acesso aos materiais é uma dimensão que incluiu brinquedos, equipamentos, livros, blocos e instrumentos para música, avaliando se estão disponíveis, acessíveis e adequados às crianças pequenas. Essa dimensão descreve recursos importantes para uma prática pedagógica rica em oportunidades de expressão e aprendizagem. Ter acesso aos materiais é um ponto central do planejamento de oportunidades adequadas para o processo de aprendizagem de crianças que frequentam o berçário e o maternal. Contudo, não basta a disponibilidade dos materiais: é preciso que eles sejam acessíveis, para despertar interações e desencadear a aprendizagem. Portanto, livros, brinquedos variados (que devem ser descritos no $\mathrm{SM}$ ) para diferentes fins (que devem refletir o currículo), materiais que fomentam atividades artísticas, físicas e cognitivas devem estar presentes em salas de berçários e maternais.

\section{QUADRO 1}

\begin{tabular}{|c|c|c|}
\hline \multicolumn{3}{|c|}{ Aspectos a serem considerados em "Acesso a materiais" } \\
\hline 1 & Há livros & \multirow{10}{*}{$\begin{array}{l}\text { São adequados e estão } \\
\text { acessíveis às crianças } \\
\text { diariamente? }\end{array}$} \\
\hline 2 & $\begin{array}{l}\text { Há brinquedos macios para relaxamento e } \\
\text { conforto }\end{array}$ & \\
\hline 3 & Há brinquedos para areia/água & \\
\hline 4 & Há equipamentos para atividade livre & \\
\hline 5 & Há blocos & \\
\hline 6 & Há materiais para música & \\
\hline 7 & Há materiais para atividade livre & \\
\hline 8 & $\begin{array}{l}\text { Há materiais para atividade de ciências e } \\
\text { natureza }\end{array}$ & \\
\hline 9 & Há materiais para atividade de faz de conta & \\
\hline 10 & Há materiais para atividade motora fina & \\
\hline
\end{tabular}




\section{ECERS-R}

Na análise clássica dos itens da escala ECERS-R, 122 indicadores foram selecionados como aqueles que mais influenciaram as pontuações obtidas nas 116 turmas avaliadas. Na análise dos resultados, agruparam-se aqueles com maior afinidade com relação a seus temas centrais, seguindo os mesmos procedimentos realizados com os resultados apresentados da ITERS-R. Esses agrupamentos foram reclassificados como mostra a primeira coluna da Tabela 4, gerando dez dimensões. As sugestões de aspectos a serem considerados na elaboração de um SM foram, então, extraídas dos indicadores de cada dimensão após a identificação dos temas centrais de cada indicador.

\section{TABELA 4}

\begin{tabular}{|c|c|}
\hline DIMENSÕES - ECERS-R & $\begin{array}{l}\text { NÚMERO DE } \\
\text { INDICADORES } \\
\text { SELECIONADOS } \\
\text { PELA ANÁLISE }\end{array}$ \\
\hline $\begin{array}{l}\text { Organização do trabalho pedagógico: inclui aspectos que ressaltam questões curriculares, isto é, } \\
\text { a presença do brincar e de atividades adequadas à faixa etária das crianças, relacionadas às várias } \\
\text { áreas do conhecimento. }\end{array}$ & 21 \\
\hline $\begin{array}{l}\text { Atitudes da equipe: referem-se às ações da equipe para promover a aprendizagem, garantir } \\
\text { segurança, desenvolver interações entre as crianças e entre adultos e crianças de forma positiva e } \\
\text { com fins educativos. }\end{array}$ & 19 \\
\hline $\begin{array}{l}\text { Acesso aos materiais: ressalta a importância de materiais e brinquedos, que representem as } \\
\text { diversas áreas do conhecimento, e que estejam ao alcance das crianças, observando-se a } \\
\text { necessidade de rodízio e troca ao longo do ano, com base na avaliação dos interesses delas. }\end{array}$ & 18 \\
\hline $\begin{array}{l}\text { Práticas de cuidado: refere-se a questões de higiene das crianças e também dos adultos, } \\
\text { ressaltando a adequação dos ambientes para a higiene pessoal e para as refeições, assim como o } \\
\text { fomento da autonomia das crianças no cuidado de si mesmas. Inclui também itens que consideram } \\
\text { os cuidados com a segurança. }\end{array}$ & 17 \\
\hline $\begin{array}{l}\text { Uso da linguagem: reúne itens que exploram atitudes da equipe em relação às crianças para: } \\
\text { introduzir e expandir conhecimentos; interagir e encorajá-las a se comunicarem; participar de suas } \\
\text { brincadeiras, intentando desencadear e efetivar aprendizagens. }\end{array}$ & 12 \\
\hline $\begin{array}{l}\text { Estratégias para desenvolvimento profissional: reúne aspectos relacionados à autoavaliação, } \\
\text { supervisão e observação do trabalho da equipe; reuniões para supervisão; ações de formação } \\
\text { profissional e retorno das observações e avaliações, ressaltando a frequência das observações e } \\
\text { das reuniões para conversas. }\end{array}$ & 11 \\
\hline $\begin{array}{l}\text { Organização do ambiente: descreve a organização da sala quanto à possibilidade de desenvolver } \\
\text { atividades consecutivas, por meio das áreas de interesse (ou cantinhos) para que as crianças } \\
\text { possam brincar de forma independente ou em pequenos grupos. }\end{array}$ & 8 \\
\hline $\begin{array}{l}\text { Organização do tempo: refere-se ao modo de organização do dia das crianças, ressaltando a } \\
\text { importância de promover momentos diferenciados, que atendam às diferentes necessidades e } \\
\text { interesses das crianças e que fomentem interações positivas. }\end{array}$ & 8 \\
\hline $\begin{array}{l}\text { Espaço e mobiliário: valoriza aspectos relacionados aos recursos disponíveis na unidade, tais } \\
\text { como: mobiliário que promova relaxamento e conforto para as crianças; equipamentos para } \\
\text { motricidade ampla; móveis para cuidados de rotina e acessibilidade dos ambientes para pessoas } \\
\text { com deficiência. }\end{array}$ & 7 \\
\hline \multirow[t]{2}{*}{$\begin{array}{l}\text { Estratégias para envolvimento dos pais: reúne três importantes maneiras de se desenvolver uma } \\
\text { parceria efetiva com os pais: troca de informações constantes sobre as crianças; divulgação da } \\
\text { proposta pedagógica da unidade; e convite aos pais para participar das atividades com as crianças. }\end{array}$} & 3 \\
\hline & 124 \\
\hline
\end{tabular}


ORGANIZAÇÃO DO AMBIENTE

Para exemplificar o processo de análise, será apresentada a dimensão organização do ambiente. Os indicadores selecionados pela análise clássica estão na Tabela 5.

TABELA 5

\begin{tabular}{|c|c|c|c|c|c|c|c|}
\hline SUBESCALA & ITEM & DESCRIÇÃO DOS INDICADORES & $\begin{array}{c}\text { ÍNDICE DE } \\
\text { DISCRIMINAÇÃO }\end{array}$ & $\%$ ACERTO & GI & GS & $\begin{array}{c}\text { PONTO } \\
\text { BISSERIAL }\end{array}$ \\
\hline Atividades & $\begin{array}{l}24 \text { - Brincadeira } \\
\text { de faz de conta }\end{array}$ & $\begin{array}{l}\text { 3.3 - Há um espaço separado, } \\
\text { próprio para arrumar os } \\
\text { materiais para as brincadeiras } \\
\text { de faz de conta }\end{array}$ & 0.688 & 0.560 & 0.156 & 0.844 & 0.545 \\
\hline $\begin{array}{l}\text { Espaço e } \\
\text { mobiliário }\end{array}$ & $\begin{array}{l}\text { O7- Espaço para } \\
\text { motricidade ampla }\end{array}$ & $\begin{array}{l}5.3 \text { - O espaço está } \\
\text { organizado de forma que os } \\
\text { diferentes tipos de atividade } \\
\text { não interfiram uns nos outros } \\
\text { (ex.: brincar com brinquedos } \\
\text { de roda separadamente dos } \\
\text { equipamentos de escalar e } \\
\text { jogos com bola). }\end{array}$ & 0.509 & 0.362 & 0.097 & 0.606 & 0.443 \\
\hline $\begin{array}{l}\text { Espaço e } \\
\text { mobiliário }\end{array}$ & $\begin{array}{l}\text { O4 - Organização } \\
\text { da sala para } \\
\text { atividades }\end{array}$ & $\begin{array}{l}5.1 \text { - Há pelo menos três } \\
\text { áreas de interesse definidas e } \\
\text { convenientemente equipadas } \\
\text { (ex.: água perto da área de } \\
\text { expressão plástica; estantes } \\
\text { adequadas para blocos e } \\
\text { materiais de manipulação). }\end{array}$ & 0.695 & 0.328 & 0.032 & 0.727 & 0.559 \\
\hline $\begin{array}{l}\text { Espaço e } \\
\text { mobiliário }\end{array}$ & $\begin{array}{l}\text { O4 - Organização } \\
\text { da sala para } \\
\text { atividades }\end{array}$ & $\begin{array}{l}5.3 \text { - O espaço está organizado } \\
\text { de forma que a maioria } \\
\text { das atividades não seja } \\
\text { interrompida (ex.: estantes } \\
\text { colocadas para que as crianças } \\
\text { circundem as atividades e não } \\
\text { as atravessem; a disposição do } \\
\text { mobiliário desencoraja corridas } \\
\text { ou brincadeiras violentas). }\end{array}$ & 0.636 & 0.267 & 0.000 & 0.636 & 0.519 \\
\hline $\begin{array}{l}\text { Espaço e } \\
\text { mobiliário }\end{array}$ & $\begin{array}{l}\text { O4 - Organização } \\
\text { da sala para } \\
\text { atividades }\end{array}$ & $\begin{array}{l}3.1 \text { - Pelo menos duas áreas de } \\
\text { interesse estão definidas. }\end{array}$ & 0.619 & 0.647 & 0.290 & 0.909 & 0.500 \\
\hline $\begin{array}{l}\text { Espaço e } \\
\text { mobiliário }\end{array}$ & $\begin{array}{l}\text { O4 - Organização } \\
\text { da sala para } \\
\text { atividades }\end{array}$ & $\begin{array}{l}7.2 \text { - As áreas estão } \\
\text { organizadas para que as } \\
\text { crianças as utilizem de forma } \\
\text { independente (ex.: estantes } \\
\text { abertas e etiquetadas, caixas } \\
\text { para brinquedos etiquetadas; } \\
\text { as estantes abertas não estão } \\
\text { superlotadas; o espaço para } \\
\text { brincar está próximo da área } \\
\text { onde os brinquedos são } \\
\text { guardados). }\end{array}$ & 0.602 & 0.336 & 0.065 & 0.667 & 0.492 \\
\hline $\begin{array}{l}\text { Espaço e } \\
\text { mobiliário }\end{array}$ & $\begin{array}{l}\text { O4 - Organização } \\
\text { da sala para } \\
\text { atividades }\end{array}$ & $\begin{array}{l}1.1 \text { - Não há áreas de interesse } \\
\text { definidas. }\end{array}$ & 0.550 & 0.707 & 0.419 & 0.970 & 0.458 \\
\hline
\end{tabular}


A dimensão organização do ambiente chama a atenção para a organização da sala, a fim de verificar se o espaço permite desenvolver atividades consecutivas, por meio das áreas de interesse (ou cantinhos) para que as crianças possam brincar de forma independente ou em pequenos grupos.

QUADRO 2

\begin{tabular}{|c|c|}
\hline \multicolumn{2}{|c|}{ ASPECTOS A SEREM CONSIDERADOS EM “ORGANIZAÇÃO DO AMBIENTE” } \\
\hline 1 & Há áreas de interesse (cantinhos) na sala? \\
\hline 2 & As áreas de interesse estão bem organizadas para uso independente das crianças? \\
\hline 3 & A área para motricidade ampla é organizada de modo que uma atividade não interfira em outra? \\
\hline
\end{tabular}

\section{SUGESTÕES DE CAMPOS PARA O MONITORAMENTO DAS POLÍTICAS E PRÁTICAS EDUCATIVAS}

Com base na análise estatística realizada e na compilação de dados de diferentes fontes sobre o funcionamento da rede municipal de educação infantil do Rio de Janeiro, mapearam-se alguns campos em que o monitoramento das políticas e práticas educativas poderia garantir avanços importantes na qualidade do ensino oferecido às crianças.

Vale ressaltar, mais uma vez, que a natureza dos instrumentos estabelece restrições à definição de todos os campos em que deveria incidir um processo de monitoramento das políticas e práticas educativas e que, portanto, a seleção apresentada aqui precisará certamente ser complementada com outras formas de levantamento de dados que a rede já possui (como a disponibilidade de recursos humanos; acesso etc.). Isso significa reconhecer e cuidar adequadamente das diferentes formas de coleta e sistematização das informações sobre a rede, desde sistemas federais (censo escolar, censo do IBGE, outros levantamentos do Inep etc.), passando por bases de dados estaduais para chegar às bases de dados que já estão organizadas ou precisariam ser organizadas em nível local pela SME. Em um movimento sistêmico, somente com esse conjunto de dados disponível é que se torna possível 
contextualizar e dar sentido a cada dimensão da informação ou a cada análise singular de uma dada situação explicitada em um indicador. Também é preciso situar essa sugestão de dimensões para o monitoramento dentro das possibilidades, das limitações e dos interesses da rede de ensino municipal para a qual se trabalha.

Compreendendo-se a formulação e a implementação das políticas educacionais como processos dinâmicos, tensos e negociados entre diferentes sujeitos e atores, coerentemente, é necessário assumir o monitoramento das políticas educacionais de forma a considerar a imprescindível relação dialógica e dialética entre três instâncias distintas da concretização dessas políticas: a gestão dos sistemas e das redes de ensino (no nível central e nos níveis intermediários), a gestão das unidades escolares e a gestão das práticas pedagógicas.

A garantia do efetivo direito à educação (acesso, permanência com aprendizagem e sucesso na escolarização) depende, sempre, da integração de esforços e contribuições dessas três instâncias com suas características, limitações e possibilidades. Não seria razoável atribuir a uma das três instâncias responsabilidade exclusiva para com a garantia desse direito.

Nessa perspectiva, o quadro abaixo apresenta, na primeira coluna, as dimensões em que se considera assertiva a incidência do monitoramento. Na sequência, três colunas apresentam exemplos de indicadores nos três níveis de concretização da política educacional. Cabe destacar que esses exemplos não esgotam, evidentemente, os observáveis que podem ser propostos em cada um dos campos. Ademais, a lista de possíveis indicadores em cada campo deve ser considerada à luz das possibilidades concretas da coleta e da análise de dados. 
QUADRO 3

\begin{tabular}{|c|c|c|c|}
\hline \multirow{2}{*}{ DIMENSÃO } & \multicolumn{3}{|c|}{ NÍVEIS DE CONCRETIZAÇÃO DA POLÍTICA EDUCACIONAL } \\
\hline & $\begin{array}{c}\text { GESTÃO DO SISTEMA } \\
\text { DE ENSINO }\end{array}$ & $\begin{array}{c}\text { GESTÃO DAS UNIDADES } \\
\text { ESCOLARES }\end{array}$ & $\begin{array}{c}\text { GESTÃO DAS PRÁTICAS } \\
\text { PEDAGÓGICAS }\end{array}$ \\
\hline Prédios e espaços & $\begin{array}{l}\text { A construção de prédios } \\
\text { escolares atende aos padrões } \\
\text { básicos de infraestrutura } \\
\text { previstos pelo MEC. }\end{array}$ & $\begin{array}{l}\text { A gestão escolar garante } \\
\text { que os espaços educativos } \\
\text { funcionem plenamente e } \\
\text { promovam interações e } \\
\text { atividades adequadas. }\end{array}$ & $\begin{array}{l}\text { Professores e auxiliares } \\
\text { estabelecem, em sua rotina, a } \\
\text { possibilidade da circulação dos } \\
\text { bebês e das crianças em diferentes } \\
\text { espaços da unidade escolar. }\end{array}$ \\
\hline $\begin{array}{l}\text { Estratégias de } \\
\text { desenvolvimento } \\
\text { profissional e } \\
\text { condições } \\
\text { de trabalho e carreira }\end{array}$ & $\begin{array}{l}\text { O sistema de ensino prevê } \\
\text { programas de formação } \\
\text { continuada para todos da } \\
\text { equipe pedagógica dentro da } \\
\text { jornada regular de trabalho. }\end{array}$ & $\begin{array}{l}\text { A gestão escolar organiza } \\
\text { espaços e tempos adequados } \\
\text { para a formação em serviço. }\end{array}$ & $\begin{array}{l}\text { Professores e auxiliares } \\
\text { participam com assiduidade } \\
\text { dos momentos de formação } \\
\text { continuada. }\end{array}$ \\
\hline $\begin{array}{l}\text { Estratégias para o } \\
\text { envolvimento dos pais }\end{array}$ & $\begin{array}{l}\text { O sistema de ensino prevê } \\
\text { formas de articulação da política } \\
\text { educacional com as demais } \\
\text { políticas sociais de apoio e } \\
\text { atenção às famílias (assistência } \\
\text { social, saúde, habitação, } \\
\text { segurança pública etc.). }\end{array}$ & $\begin{array}{l}\text { As unidades escolares } \\
\text { acolhem adequadamente } \\
\text { as famílias que apresentam } \\
\text { alta vulnerabilidade social, } \\
\text { inscrevendo-as na rede de } \\
\text { direitos e políticas sociais } \\
\text { adequadamente. }\end{array}$ & $\begin{array}{l}\text { Professores e auxiliares } \\
\text { encaminham adequadamente, com } \\
\text { a gestão escolar, os casos em que } \\
\text { identificam alta vulnerabilidade } \\
\text { social nas famílias das crianças ou } \\
\text { situações familiares que colocam a } \\
\text { criança em risco. }\end{array}$ \\
\hline $\begin{array}{l}\text { Organização do } \\
\text { trabalho pedagógico }\end{array}$ & $\begin{array}{l}\text { O sistema de ensino } \\
\text { estabelece, divulga e dissemina } \\
\text { proposta curricular com } \\
\text { orientações para o trabalho } \\
\text { pedagógico com bebês e } \\
\text { crianças pequenas para toda a } \\
\text { rede de ensino. }\end{array}$ & $\begin{array}{l}\text { O projeto pedagógico da } \\
\text { escola está alinhado com } \\
\text { as diretrizes curriculares } \\
\text { nacionais e com as } \\
\text { orientações curriculares } \\
\text { municipais estabelecidas } \\
\text { para a educação infantil do } \\
\text { município. }\end{array}$ & $\begin{array}{l}\text { Professores e auxiliares elaboram } \\
\text { o plano de atividades que } \\
\text { desenvolvem com bebês e } \\
\text { crianças pequenas ancorado } \\
\text { nas orientações curriculares } \\
\text { do município e no projeto } \\
\text { pedagógico da unidade/escola. }\end{array}$ \\
\hline $\begin{array}{l}\text { Linguagem oral e } \\
\text { escrita }\end{array}$ & $\begin{array}{l}\text { O sistema de ensino assegura } \\
\text { a existência de condições } \\
\text { objetivas que garantam a } \\
\text { circulação de diferentes } \\
\text { suportes da linguagem escrita } \\
\text { na escola (livros, revistas, } \\
\text { jornais, computadores etc.). }\end{array}$ & $\begin{array}{l}\text { As unidades escolares } \\
\text { garantem que os diferentes } \\
\text { suportes da linguagem escrita } \\
\text { estejam acessíveis e em bom } \\
\text { estado para a utilização pelos } \\
\text { bebês e pelas crianças. }\end{array}$ & $\begin{array}{l}\text { Professores e auxiliares oferecem } \\
\text { às crianças momentos e situações } \\
\text { bem planejados de contato } \\
\text { com os diferentes suportes da } \\
\text { linguagem escrita. }\end{array}$ \\
\hline Atividades & $\begin{array}{l}\text { Materiais, equipamentos e } \\
\text { brinquedos são adquiridos } \\
\text { regularmente para distribuição } \\
\text { equitativa na rede. }\end{array}$ & $\begin{array}{l}\text { As unidades garantem a } \\
\text { distribuição de equipamentos, } \\
\text { materiais e brinquedos para o } \\
\text { desenvolvimento de atividades } \\
\text { conforme previsto no projeto } \\
\text { pedagógico da unidade. }\end{array}$ & $\begin{array}{l}\text { Professores e auxiliares garantem } \\
\text { que todas as crianças utilizem } \\
\text { os equipamentos, materiais } \\
\text { e brinquedos durante o } \\
\text { desenvolvimento de atividades } \\
\text { nos vários espaços da unidade. }\end{array}$ \\
\hline
\end{tabular}

Pretende-se aqui enfatizar o fato de que todas as ações desenvolvidas para e com as crianças no espaço da unidade estão diretamente relacionadas com a cadeia de ações advindas das políticas estabelecidas pelo município em uma relação de cooperação e coautoria entre os gestores e a equipe pedagógica. Constituem essa cadeia de ações todas as questões relacionadas aos profissionais da SME e suas diferentes funções e atribuições; ações de formação; a legislação e a documentação produzidas para o funcionamento da rede e das unidades; as condições da infraestrutura atual (e em construção) e sua manutenção; as orientações curriculares e pedagógicas elaboradas pela SME, discutidas e distribuídas em rede; o fornecimento / a aquisição e a substituição de materiais, brinquedos, livros e equipamentos; a disponibilidade 
de recursos financeiros; a infraestrutura para alimentação, cuidado e sono; a segurança e a proteção de todos em seus locais de trabalho.

Embora haja diferenças nas atribuições de cada instância da rede municipal, todas elas contribuem para a formação dessa cadeia de ações, e o sucesso dela depende da sintonia entre as diferentes instâncias, tais como a Secretaria em si, as regionais (no caso de cidades grandes) e as unidades de atendimento. Apesar de haver diferenças expressivas entre as unidades de uma rede municipal, estas não podem, no entanto, ser produto de negligência, omissão ou dificuldade de um dos níveis de gestão; pelo contrário, devem decorrer das diferenças contextuais e da demanda expressa pela e na comunidade em que as unidades estão inseridas. Compreendendo-as dessa forma, as necessidades das unidades e suas dificuldades em executar seu plano de ação devem ser tratadas de maneira a minimizar as diferenças de cunho administrativo e de gestão pedagógica atendendo às demandas do grupo das unidades em questão. Esse movimento de interpretar e executar as políticas em conjunto faz parte do processo de melhoria da qualidade do trabalho com crianças pequenas. É, portanto, no fluxo dessa cadeia que o monitoramento deve centrar-se. Esforços devem ser feitos para tornar visível esse fluxo, de maneira a possibilitar o controle das ações tanto no nível da gestão como na esfera das práticas pedagógicas.

\section{CONSIDERAÇÕES FINAIS}

É importante acrescentar algumas recomendações que surgiram ao longo do processo de elaboração deste estudo a respeito da concepção e da implementação de um sistema de monitoramento (SM). Em primeiro lugar, é muito importante ter claro que o SM deve ser constantemente revisto e atualizado, uma vez que as práticas evoluem e as políticas vão também sendo revistas, reelaboradas e complementadas. Assim, o sistema deve estar concebido de modo a ser orgânico, flexível e passível de mudanças ao longo do tempo.

Em segundo lugar, é necessário formular um sistema que contenha informações já existentes e produzidas pela própria 
rede. Com base nos dados que são rotineiramente coletados, pode-se criar indicadores representativos e sucintos que facilitem a interpretação da realidade por parte dos gestores e de outros profissionais que atuam na rede. Note-se aqui que, nessa etapa do presente estudo, os indicadores não chegaram a ser elaborados, e a análise aqui apresentada levantou possíveis e importantes tópicos a serem considerados na lista de indicadores.

Em terceiro lugar, é fundamental o envolvimento de profissionais de todos os níveis no processo de elaboração, implementação, alimentação e acompanhamento do SM. Isso garantirá a definição de indicadores relevantes e pertinentes à rede e que revelem elementos a serem priorizados na tomada de decisões. Tornando-se uma ferramenta de gestão para todos os níveis de concretização da política (Secretaria de Educação, regionais e unidades), o monitoramento pode ter um caráter formativo, que, por sua vez, leve ao aperfeiçoamento do trabalho desenvolvido pelos profissionais nos diversos níveis. Por fim, vale ressaltar que, como uma política de acompanhamento, o monitoramento da educação infantil terá sentido apenas se incluir a voz de todos os principais protagonistas desse importante dever do Estado e direito das crianças.

\section{REFERÊNCIAS}

BECCHI, E.; BONDIOLI, A. Avaliando a pré-escola: uma trajetória de formação de professoras. Campinas: Autores Associados, 2003.

BHERING, E. et al. Ambientes de unidades municipais de educação infantil do Rio de Janeiro: uma proposta de formação e avaliação. Relatório de Pesquisa. São Paulo: Fundação Carlos Chagas, 2013.

BLOOM, S. S. Violence against women and girls: A Compendium of Monitoring and Evaluation Indicators. United States Agency for International Development (Usaid), 2008. Disponível em: <www.awid.org/Library/Violenceagainst-Women-and-Girls-a-Compendium-of-Monitoring-and-EvaluationIndicators>. Acesso em: 24 jan. 2014.

BRASIL. Ministério da Educação. Secretaria da Educação Básica. Educação infantil: subsídios para a construção de uma sistemática de avaliação. Brasília: MEC/SEB, 2012.

. Indicadores da qualidade da educação infantil. Brasília: MEC/SEB, 2009. Parâmetros nacionais de qualidade para a educação infantil. Brasília:

MEC/SEB, 2006. 
CAMPOS, M. M. et al. Educação infantil no Brasil: avaliação qualitativa e quantitativa. Relatório de Pesquisa. São Paulo: Fundação Carlos Chagas, 2010.

CAMPOS, M. M.; ROSEMBERG, F. Critérios para um atendimento em creches que respeite os direitos fundamentais das crianças. Brasília: MEC/SEF/DPE/COEDI, 1995.

GENTILI, P. P. A. O discurso da qualidade como nova retórica conservadora no campo educacional. In: GENTILI, P. A. A.; SILVA, T. T. Neoliberalismo, qualidade total e educação: visões críticas. Petrópolis: Vozes, 2001.

HARMS, T.; CLIFFORD, M.; CRYER, D. Infant/toddler environment rating scale. Rev. ed. New York: Teachers College, 2005.

Early childhood environment rating scale. Rev. ed. New York: Teachers College, 2006.

JANUZZI, P. et al. Estruturação de sistemas de monitoramento e especificação de pesquisas de avaliação: os problemas de programas públicos no Brasil. In: FRANZESE, C. et al. Reflexões para Ibero-América: avaliação de programas sociais. Brasília: Enap, 2009.

MOKATE, K. M. Convirtiendo el "monstruo" en aliado: la evaluación como herramienta de la gerencia social. Revista do Serviço Público, Brasília, v. 53, n. 1, p. 89-131, jan./mar. 2002.

RIO DE JANEIRO. Secretaria Municipal de Educação. Gerência de Educação Infantil. Orientações curriculares para a educação infantil. Rio de Janeiro: SME/GEI, 2013.

ELIANA BHERING

Professora da Faculdade de Educação da Universidade Federal do Rio de Janeiro (FE-UFRJ). Pesquisadora Sênior da Fundação Carlos Chagas

ebhering@yahoo.com

BEATRIZ DE OLIVEIRA ABUCHAIM

Pesquisadora da Fundação Carlos Chagas

babuchaim@fcc.org.br 
$\overline{\mathbf{T}}$

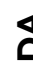

㟧

宸

西

$\sum^{\frac{m}{2}}$

㟔

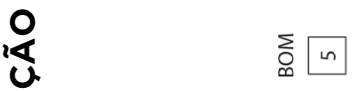

s

交

щ

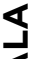

త্

ш

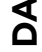

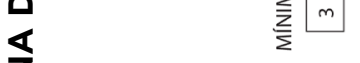

$\frac{z}{5}$

a

$\stackrel{\overleftarrow{\Sigma}}{5}$

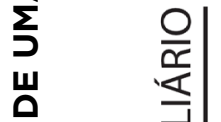

$\sum^{0}$

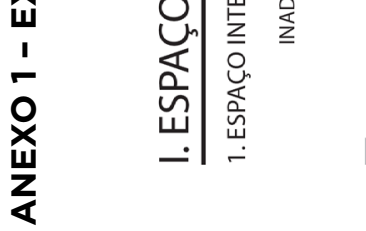

$\bullet$

$\nabla$

N
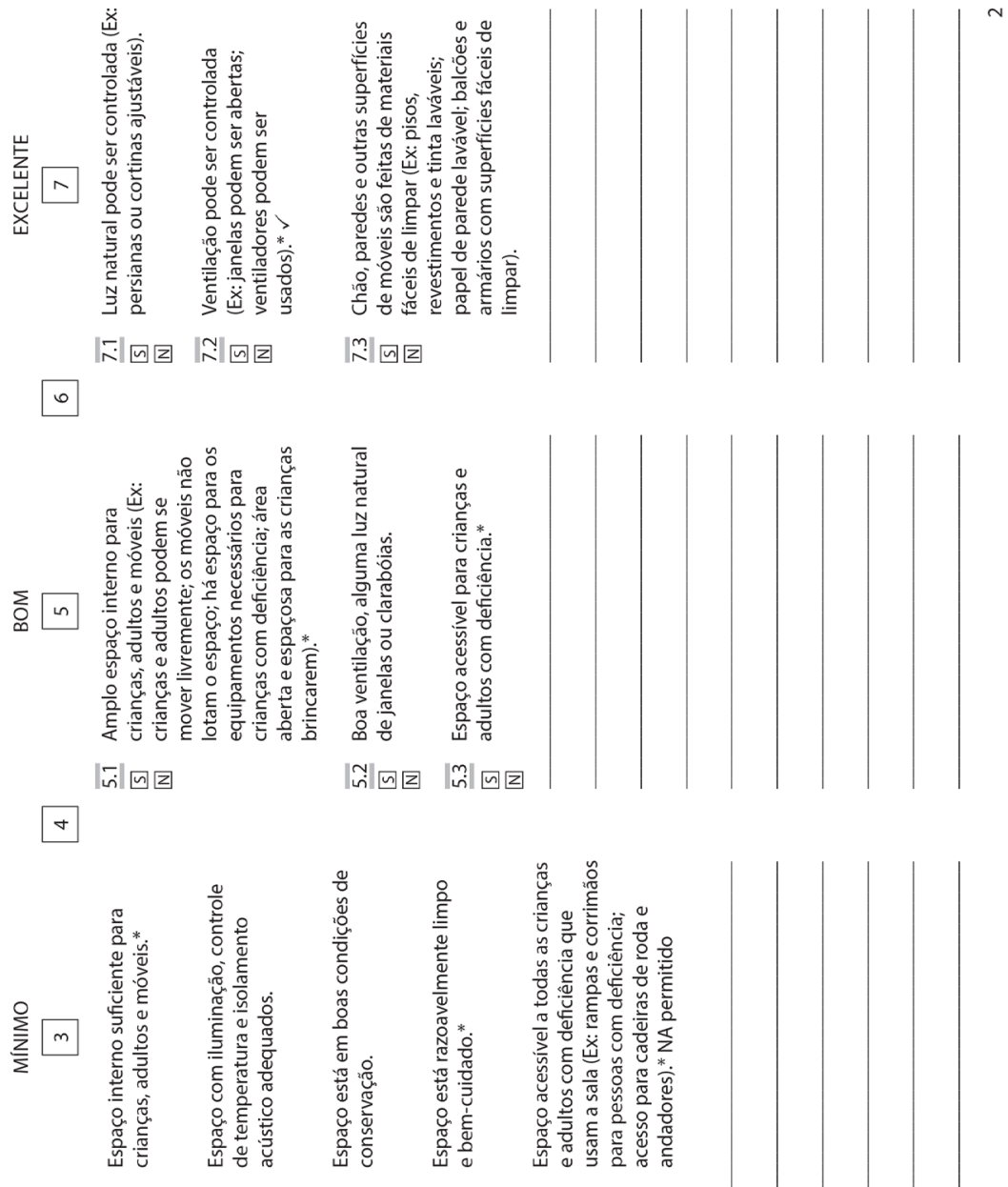

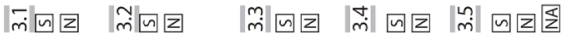
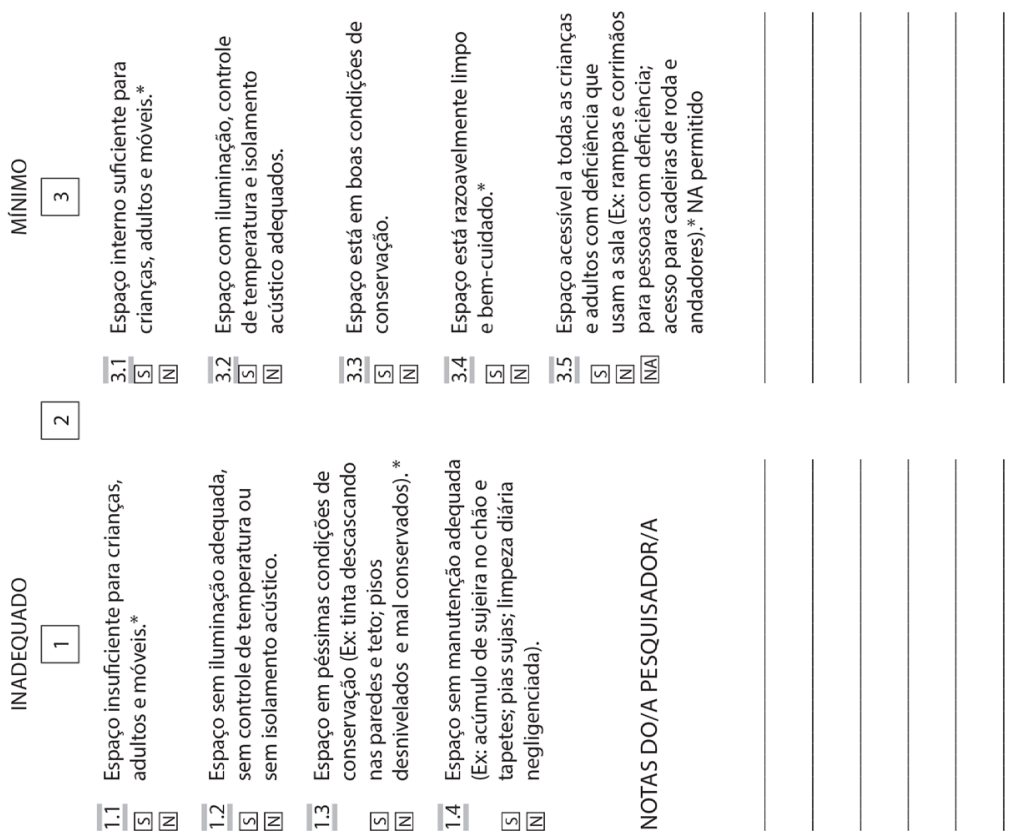

Recebido em: JULHO 2014

Aprovado para publicação em: AGOSTO 2014 